\title{
ANNOTATIONS
}

\section{Standards of Vision}

Readers will be interested to have before them the latest standards of vision for candidates wishful to enter the Royal Air Force or the Army as officers.

\section{ARMY}

Officers (Permanent, Temporary, Special Reserve, and T.F.)

(I) A candidate for a commission will be considered fit if his vision without the aid of glasses is not less than 6/60 with each eye, provided that with the aid of glasses, if necessary, his vision is not less than 6/9 in one eye (R. or L.) and 6/18 in the other.

(II) A candidate for a commission will be considered fit if he has one eye (R. or L.) with vision of not less than $2 / 60$, and with a good field of vision as tested by hand movements, provided that his vision in the other eye is $6 / 6$, or not less than $6 / 12$ without glasses and capable of correction to $6 / 6$ with the aid of glasses.

\section{ROYAL AIR FORCE}

(a) Distant vision either eye, V. 6/6. Latent hypermetropia of 2D. or more shall disqualify.

(b) Both eyes must have good fields of vision as tested by hand movements.

(c) Good binocular fusion and balance of the eye muscles.

(d) Normal colour vision according to Board of Trade standards.

We do not hesitate to characterize the Army standards set forth above, which are intended for boys entering at Sandhurst or Woolwich with a view to a career in the Army, as hopelessly inadequate, and as comparing very badly with the standards of the Royal Air Force.

\section{The Eyes of Naval Signalmen}

Dr. Alexander Duane made some valuable observations upon the eyes of the naval signalmen at the June meeting of the American Ophthalmological Society (American Journal of Ophthalmology, August, 1919). His remarks were based upon two years' experience in charge of the signal bridge of a United States warship. During that period Duane tested practically the ability of some two hundred men in working and reading signals. One hundred of the men served on the bridge under his direct supervision. It appears that a signalman must be able to recognise the meaning of more than two hundred flags. Flags are recognised by $(a)$ shape, (b) colour, and (c) situation. The main point of distinction should be colour, but the colours themselves leave much to be desired. 
In American flags, even when new, 'the blue is much too dark, and the red soon becomes dingy. The seriousness of faulty colouration in a flag will be at once apparent when it is realised that flag signals are intended to be read instantaneously. The author groups the conditions affecting the visibility of signals as follows: 1. Distance. 2. Illumination and background. 3. Atmospheric conditions. 4. Wind. 5. Motion of the ship. 6. Faulty technic. 7. Use of binoculars and telescopes. As to the visual requirements of the signalmen, the visual acuity is not the most important, at least, as we test it with charts. At the same time a signalman's sight must be good. If, in selected cases, men with glasses be allowed to serve on the bridge, Duane believes that the vision with the help of glasses should not be less than 20/20 in each eye, and that it might even be advisable to require $20 / 15$ in at least one eye. Duane points out the many inconveniences of wearing glasses in such an occupation. For example, they produce disturbing reflections; they readily become dimmed with moisture and marked with grease; and, even when clean, cut off enough light to render the recognition of faint distant objects more difficult. The improvement produced by glasses in distant vision is not at all comparable with that obtained with the same glasses when looking at an object at twenty feet. In Duane's own case his sight with glasses is $20 / 20$ and without them about 20/40. Yet he can make out far away flags, etc., almost, if not quite, as well without as with his glasses. The author would always consider the ocular requirements for signal work in connection with a man's mental and moral make-up and his reaction-time, together with his general physical condition. It is proposed to place candidates not immediately rejected in a probationary signal class, where the cause of their defective sight could be ascertained, and, if due to an error of refraction, corrected. The better of these men would be admitted to the bridge, even if their vision were not up to the full standard. On the other hand, even if he had perfect sight, etc., Duane would not have an the bridge a man who showed while on probation that he was erratic or quarrelsome, was untrustworthy, or who carried out his duties carelessly or perfunctorily.

\section{A Theory of Vision}

The following is taken from The Times report of the recent meeting. of the British Association at Bournemouth.:

Sir Oliver Lodge, speaking in the Mathematical Science

- Section on a possible theory of vision, suggested that in the retina of the eye there were certain atoms, perhaps in the black pigment, which were stimulated into radio-activity by the impact of waves of light of luminous fréquency. But these 
atoms when they received these waves, after accumulating energy of the right frequency, flung it away in a minute fraction of a second and thereby stimulated the nerves. The stimulation was much greater than the light which fell upon the eye, which was marvellously sensitive to light, but to no other kind of vibration. He would like an experiment to be made with the retina of an eye, if such experiment were possible with a dead eye. He would like to put the retina on an electroscope, then illuminate with red, green, or violet light, to see whether it would shoot off electrons and stimulate the electroscope. It would be a very delicate experiment, but they had very delicate instruments now.

\section{The Ophthalmic Service in the American Expeditionary Forces}

An authoritative history of the ophthalmic service in the American Expeditionary Forces was presented to the Section on Ophthalmology of the American Medical Association, by Dr. Allen Greenwood, senior consultant, on June 11, 1919 (See Amer. Jl. Ophthal., August, 1919.) It forms instructive and interesting reading. Dr. Greenwood was appointed senior consultant in ophthalmology in May, 1918, and in that month and the following he visited many of the French hospitals belonging to the A.E.F. The then conditions of those institutions are outlined in the paper before us. Much was done in seeing that the hospitals were properly equipped for eye work and setting aside certain of them for special purposes. In October, 1918, the senior consultant visited all similar institutions in England, and made suggestions upon what he saw to the American authorities. His headquarters in France were in Neufchâteau, where his colleagues were Lieut.-Col. G. S. Derby, as assistant consultant, and Lieut.-Col. Nelson M. Black, as consultant. The office of the division of ophthalmology was established at "Neufchâteau. An important and useful duty of the office/was to visit various eye clinics, and to encourage the officers employed there. Circulars for the guidance of ophthalmologists were issued from time to time by the senior consultant, and in this way useful information was disseminated about "gassed" eyes, injuries of the eye, panophthalmitis, orbital injuries, brain injuries, trachoma, refraction cases, the keeping of records, the conservation of pathological specimens, the technic of Frost's operation, and so forth. An optical base and eight auxiliary units, each having an authorized strength of one officer and thirty-six men, were organized at Camp Crane, Allentown, Pa., in March, 1918, and left the United States on April 4, 1918. They arrived in France on May 4, 1918. Nineteen tons of optical machinery were shipped from America before 